\title{
Gestational Diabetes Mellitus: Knowledge and Awareness
}

\author{
Khushboo Singh Sisodiya*, Bharti Prakash** \\ *Research Scholar, **Associate Professor, \\ Department of Zoology, S.P.C. Government College, M.D.S. University, Distt. Ajmer, Rajasthan, India. \\ Corresponding Author: Khushboo Singh Sisodiya
}

\begin{abstract}
Gestational diabetes mellitus is a disorder of glucose intolerance which occurs for the first time during pregnancy. Gestational diabetes mellitus is major public health issue which is increasing day by day all over the world. It leads to the risk of obesity, type 2 diabetes and possibly adult cardiovascular disease in infant and increases rate of caesarean delivery and prenatal injury. This preliminary study is done to analyse the knowledge and awareness about GDM in antenatal women. Data were collected from government and private hospitals like Amrit Kaur Hospital, Shree maternity Child Hospital, Jain fertility Child ICU Hospital etc. Questionnaires were given to pregnant women who Visited hospitals for antenatal check up. A total no of 250 respondents were included in this study. Of total number of women only 52\% were known to GDM. So, the knowledge about GDM is average in women and most of the women gain this knowledge from their own experience. The study reveals that health program and camps should be organized to increase the knowledge about GDM.
\end{abstract}

Keywords- Gestational Diabetes Mellitus, Awareness, cardiovascular disease

\section{INTRODUCTION}

GDM is regarded as the developing diagnostic and epidemiological hassle in current years. Gestational diabetes mellitus is a disorder of glucose intolerance which occurs for the first time during pregnancy. Gestational diabetes mellitus is major public health issue which is increasing day by day all over the world. At the time of gestation placenta release a hormone called the human placental lactogen or human chorionic somatomamotropic hormone (HCM). This hormone enables the foetus to grow and modifies the metabolism of the mother and increase the blood sugar level of the mother. It makes the mother much less attentive to insulin meaning the body of the mother is unable to use insulin properly and this decreased sensitivity to insulin increases the blood glucose level in mother. It leads to the risk of obesity, type 2 diabetes and possibly adult cardiovascular disease in infant and increases rate of caesarean delivery and prenatal injury.

Objectives- To analyse the knowledge and awareness about GDM in antenatal women.

\section{METHODS}

The present study was done in government and private hospitals of Beawar region namely Amrit Kaur Government Hospital, Shree Maternity Child Hospital and Jain fertility Child ICU Hospital. This study was conducted between the periods of six months from Jan 2019 to June 2019. All pregnant ladies who voluntarily participated in the study were included and who can't deliver response like critically ill mothers, those not able to pay attention/ speak; ladies with intellectual fitness hassle have been excluded from the study.

A total number of 250 respondents were included in this study. For the study a 
well-prepared questionnaire was given to the pregnant women who visited the hospitals for antenatal check-up. The respondents were requested to fill the questionnaire. Questionnaire contained 21 questions in all with 11 questions on awareness about GDM, and risk factors, diagnosis, treatment, and outcomes of GDM and 10 questions related to their sociodemographic details like name, age, occupation, weight etc. The source of knowledge about GDM were also obtained. All questions had categorical responses (yes and no) and were implemented with an item score of ' 1 ', ' 0 ' respectively. All respondents who replied 'Yes' had been given rating of ' 1 ' and those who answered 'No' were given a rating of ' 0 '. Each correct response was given a rating of 1 and each woman became scored out of a complete of 11. A rating of $0-4$ was taken into consideration as poor information, 5-8 as fair, and 9-11 as excellent knowledge of GDM. The average score of mothers on understanding of GDM and its chance elements, screening and treatment and consequences of GDM were calculated.

\section{RESULT}

Table 1: Knowledge about GDM and its risk factors, diagnosis, treatment and outcomes in antenatal women

\begin{tabular}{|l|c|c|}
\hline \multicolumn{1}{|c|}{ Questions } & \multicolumn{2}{|c|}{$\begin{array}{l}\text { Participants } \\
\text { replied 'yes' } \\
\text { (Respondents- 250) }\end{array}$} \\
\cline { 2 - 3 } & n & \% \\
\hline $\begin{array}{l}\text { Knowledge about Diabetes } \\
\text { Mellitus }\end{array}$ & 219 & 87.6 \\
\hline $\begin{array}{l}\text { Awareness about Gestational } \\
\text { Diabetes Mellitus }\end{array}$ & 130 & 52 \\
\hline Knowledge of causes of GDM & 90 & 36 \\
\hline $\begin{array}{l}\text { Is Obesity is a risk-factor for } \\
\text { GDM? }\end{array}$ & 150 & 60 \\
\hline $\begin{array}{l}\text { Is GDM history is a risk factor for } \\
\text { the Diabetes in future Pregnancy? }\end{array}$ & 122 & 48.8 \\
\hline $\begin{array}{l}\text { Have you know about Oral } \\
\text { Glucose Tolerance Test? }\end{array}$ & 83 & 33.2 \\
\hline $\begin{array}{l}\text { Is treatment is necessary to cure } \\
\text { GDM? }\end{array}$ & 95 & 38 \\
\hline $\begin{array}{l}\text { Is only diet and exercise can treat } \\
\text { GDM? }\end{array}$ & 62 & 24.8 \\
\hline Is insulin is required to cure GDM? & 165 & 66 \\
\hline $\begin{array}{l}\text { Does GDM cured after parturition } \\
\text { or not? }\end{array}$ & 79 & 31.6 \\
\hline Is GDM affects baby's health? & 142 & 56.8 \\
\hline $\begin{array}{l}\text { Does history of GDM develops } \\
\text { type 2 Diabetes in future? }\end{array}$ & 61 & 24.4 \\
\hline
\end{tabular}

250 antenatal mothers have been filled the questionnaire and only 52\% knew about GDM. Overall, 24\% women had good information, 54\% had little knowledge, and $22 \%$ had weak knowledge of GDM. The median knowledge rating changed into 6.5. The previous knowledge of GDM was known to only a few ladies through tv/radio, own family members, Doctors, friends and neighbors and newspapers.

\begin{tabular}{|l|c|c|}
\hline \multicolumn{1}{|c|}{ Table 2: Sources of knowledge about GDM } \\
\hline & $\begin{array}{l}\text { Participants who } \\
\text { (Respondents- 250) }\end{array}$ & replied 'yes' \\
\cline { 2 - 3 } & $\mathbf{n}$ & $\mathbf{\%}$ \\
\hline Family members & 38 & 15.2 \\
\hline $\begin{array}{l}\text { Neighbors and } \\
\text { friends }\end{array}$ & 41 & 16.4 \\
\hline Tv/Radio & 27 & 10.8 \\
\hline News paper & 29 & 11.6 \\
\hline Doctors & 115 & 46 \\
\hline
\end{tabular}

Table 3: Knowledge about GDM

\begin{tabular}{|l|c|c|}
\hline Score & n & Percentage \\
\hline Good knowledge (0-4) & 55 & $22 \%$ \\
\hline Average knowledge (5-8) & 135 & $54 \%$ \\
\hline Weak knowledge (9-11) & 60 & $24 \%$ \\
\hline
\end{tabular}
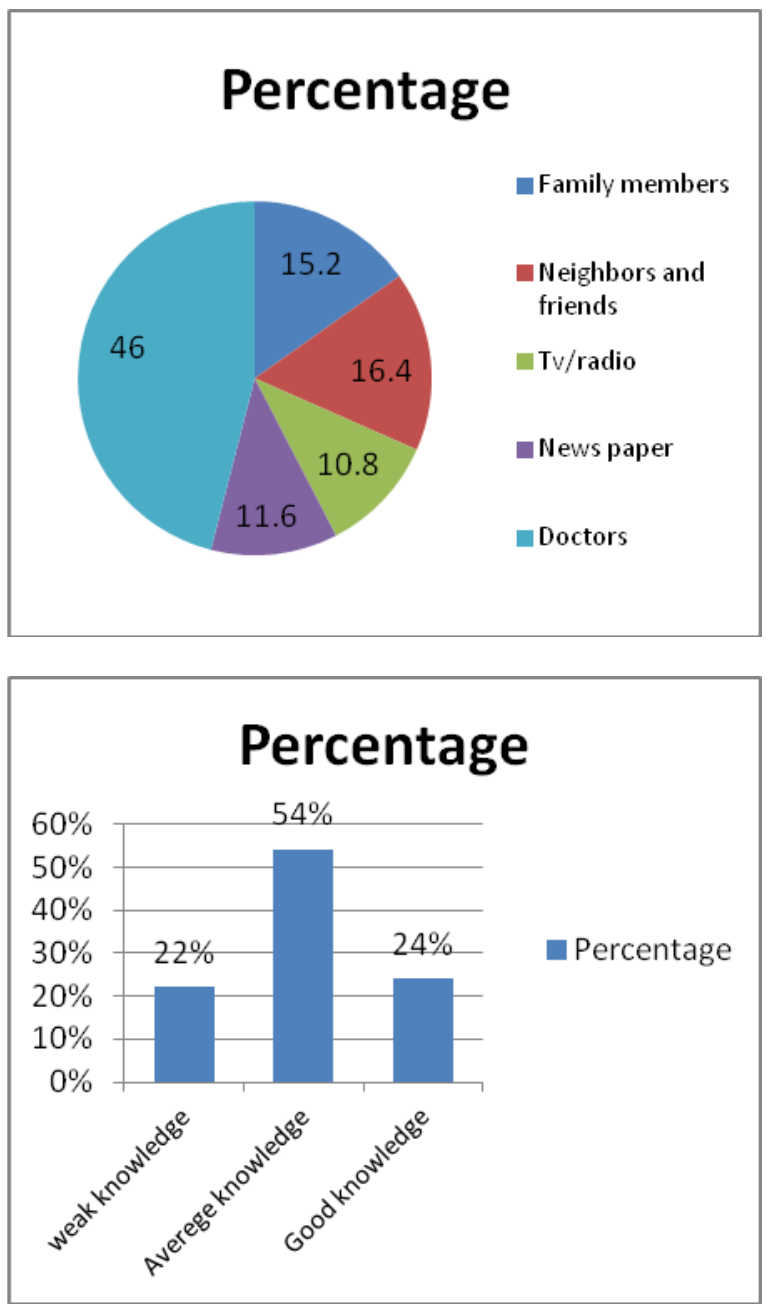


\section{DISCUSSION}

The study suggests that only $24 \%$ of the respondents had good knowledge about GDM approximately. Prevalence of GDM is increasing all over the world in conjunction with type 2 diabetes mellitus. GDM if left untreated results in extreme maternal and neonatal complications. The knowledge and proper diagnosis and treatment of GDM helps in improving health and lives of pregnant women during pregnancy and afterwards.

\section{Acknowledgement: None}

\section{Conflict of Interest: None}

\section{Source of Funding: None}

\section{Ethical Approval: Approved}

\section{REFERENCES}

1. Elamuruga S. and Arounassalam B. What do Mothers know about gestational diabetes: knowledge and awareness. Indian Journal of Obstetrics and Gynecology Research 2016;3(4):393-396.

2. Surwade V.M., Sinha V., Kachhawa P. Prevalence of Gestational Diabetes And Risk Factors Among Women Visiting Antenatal Clinic of A Tertiary Health Care Hospital. IOSR-JDMS. 2017;16(9):1-4.

3. Shriraam V., Rani M.A., Sathiyasekaran B.W.C., Mahadevan S. Awareness of gestational diabetes mellitus among antenatal women in a primary health center in South India. Indian Journal of Endocrinology and Metabolism / Jan-Feb 2013 / Vol 17 | Issue 1.

4. Lakshmi D., Felix A.J.W., Devi R., Manobharathi M. Study on knowledge about gestational diabetes mellitus and its risk factors among antenatal mothers attending care, urban Chidambaram. Int $J$ Community Med Public Health. 2018 Oct;5(10):4388-4392.

5. McIntyre H.D., Kapur A., Divakar H., Hod M. Gestational Diabetes Mellitus- Inovative approach to Prediction, Diagnosis, Management and prevention of future NCDMother and offspring. Obesity, a section of the journal Frontiers in Endocrinology 03
December 2020/ Volume 11/Article 614533.

6. Swaminathan G., Swaminathan A., Corsi D.J. Prevalence of Gestational Diabetes in India by Individual Socioeconomic, Demographic, and Clinical Factors. AMA Network Open. 2020;3(11):e2025074.

7. Catalano P.M., Mcintyre H.D., Cruickshank J.K., Mccance D.R., Dyer A.R., Metzger B.E., Lowe L.P., Trimble E.R., Coustan D.R., Hadden D.R., Persson B., Hod M., Otas J.J.N. The Hyperglycemia and Adverse Pregnancy Outcome Study. Diabetes Care 35:780-786, 2012

8. Thathagari, V., Doddaiah, V. and Raghavenda, B. (2016): A study of prevalence and determinants of gestational diabetes mellitus. Int. J. Reprod. Contracept. Obstet. Gyneco., 5(6): pp. 1331-1335.

9. Saini, P., Pankaj, J. P., Jain, A. and Agarwal, G. C. (2015): Effect of GDM on gross morphology of placenta. Int. J. Anat. Res., 3(1): pp. 889-894.

10. Roy, S. B., Morin, L., Cousineau, J. and Re, E . (2012): Pregnancy outcomes in women with and without gestational diabetes mellitus according to The International Association of the Diabetes and Pregnancy Study Groups Criteria. New Gestational Diabetes Diagnostic Criteria, 120(4): pp. 746-752.

11. Raja, M. W., Baba, T. A., Hanga, A. J., Bilquees, S., Rasheed, S., Haq, I. U., Khan, S. M. S. and Bashir, A. (2014): A study to estimate the prevalence of gestational diabetes mellitus in an urban block of Kashmir valley. International Journal of Medical Science and Public Health, 3(2): pp. 191-195.

12. Rajput, R., Yadav, Y., Nanda, S. and Rajput, M. (2013): Prevalence of GDM an associated risk factors at a tertiary care hospital in Haryana. Indian J. Mad. Res., 137: pp. $728-733$.

13. Reddy, K. M., Sailaja, P. L., Balmuri, S., Jagarlamudi, A. and Betha, K. (2017): Prevalence of gestational diabetes mellitus and perinatal outcome: a rural tertiary teaching hospital based study. Int. J. Reprod. Contracept. Obstet. Gynecol., 6(8): pp. 3594-3598.

14. Lapolla, A., Dalfra, M. G. and Fedele, D. (2009): Management of gestational diabetes. 
Diabetes Metabolic Syndrome and Obesity: Targets and Therapy, 2: pp. 73-82.

15. Mithal, A., Bansal, B. and Kalra, S. (2015): Gestational diabetes in India. Indian Journal of Endocrinology and Metabolism, 19(6): pp. 701-704.

16. Nikoo, K. M., Ahranjani, A. S., Larijani, B. (2009): A review on the prevalence of gestational diabetes mellitus (GDM) in different regions of Iran. Iranian Journal of Diabetes and Lipid Disorders, pp. 47-56.

17. Nilofer, A. R., Raju, V. S., Dakshayini, B. R. and Zaki, S. A. (2012): Screening in high-risk group of gestational diabetes mellitus with its maternal and foetal outcomes. Indian J. Endocrinol. Metab., 16(1): 74-78.

18. Pastakia, S. D., Njuguna, B., Onyango, B. A., Washington, S., Deb, A. C., Kosgei, W. K. and Saravanan, P. (2013): Prevalence of gestational diabetes mellitus based on various screening strategies in western Kenya. BMC Pregnancy and Childbirth, 17: pp. 1-9.

19. Gracelyn, L. J. and Saranya, N. (2016): Prevalence of gestational diabetes mellitus in antenatal women and its associated risk factors. Int. J. Reprod. Contracept Obstet. Gynecol., 5(2): pp. 285-291.

20. Gopalakrishnan, V., Singh, R., Pradeep, Y., Kapoor, D., Rani, A. K., Pradhan, S., Bhatia, E. and Yadav, S.B (2015): Evaluation of the prevalence of gestational diabetes mellitus in north Indians using
IADPSG criteria. J. Poatgrad. Med., 61(3): pp. 155-158.

21. Gupta, R. and Tyagi, P. (2017): Gestational diabetes mellitus. J. Med. Physiol. Ther., 1(3): pp. 1-3.

22. Arora, G. P., Thaman, R. G., Prasad, R. B., Almgren, P., Brons, C., Groop, L. C. and Vaag, A. A. (2015): Prevalence and risk factors of gestational diabetes in Punjab, North India. Eur. J. Endocrinol., 173(2): pp. 257-267.

23. Balaji, V., Balaji, M., Anjalakshi, C., Cynthia, A., Arthi, T. and Seshiah, V. (2011): Diagnosis of gestational diabetes mellitus in Asian-Indian women. Indian $J$. Endocrinol. Metab., 15(3): pp. 187-190.

24. Bellamy, L., Casas, J. P., Hingorani, A. D. and Williams, D. (2009): Type 2 diabetes mellitus after gestational diabetes: a systematic review and meta-analysis. The Lancet, 9701, 373: pp. 1773-1779.

25. Abbasi, M., Khorasani, Z. M., Etminani, K. and Rahmanvand, R. (2017): Determination of the most important risk factors of gestational diabetes in Iran by group analytical hierarchy process. Int. J. Reprod. BioMed., 15(2): pp. 109-114.

How to cite this article: Sisodiya KS, Prakash B. Gestational diabetes mellitus: knowledge and awareness. Int J Health Sci Res. 2021; 11(11):134-137. DOI: https://doi.org/10.52403 /ijhsr.20211117 